\title{
On the impact of trade on the industrial structures of nations ${ }^{*}$
}

\author{
Daisuke Oyama $^{\dagger} \quad$ Yasuhiro Sato ${ }^{\ddagger}$ Takatoshi Tabuchi ${ }^{\S}$ \\ Jacques-François Thisse ${ }^{\mathbb{T}}$
}

First version: October 5, 2007

This version: February 15, 2010

\begin{abstract}
This paper investigates the impact of progressive trade openness on the formation of entrepreneurship in a two-country occupation choice model with monopolistic competition. We show that trade opening gives rise to a non-monotonic process of international specialization, in which the share of entrepreneurial firms in the large (small) country first increases (decreases) and then decreases (increases), with the global economy exhibiting first de-industrialization and then reindustrialization.
\end{abstract}

KEYWORDS: entrepreneurship, monopolistic competition, trade liberalization

JEL Classification: F12, F16, J24, O14, R12

\footnotetext{
${ }^{*}$ We wish to thank the Editor, an anonymous referee, and workshop/conference participants at Academia Sinica, Hitotsubashi University, Kobe University, Otaru University of Commerce, Taipei National University, University of Tokyo, and ARSC 2009 for very useful comments and suggestions. D. Oyama, Y. Sato, and T. Tabuchi acknowledge financial support by JSPS Grant-in-Aid for Young Scientists (B), Scientific Research (S), and Scientific Research (A). Part of this research was developed while D. Oyama was visiting CORE and PSE, whose hospitality is gratefully acknowledged.

${ }^{\dagger}$ Graduate School of Economics, Hitotsubashi University (Japan); oyama@econ.hitu.ac.jp

${ }^{\ddagger}$ Graduate School of Economics, Osaka University (Japan); ysato@econ.osaka-u.ac.jp

${ }^{\S}$ Faculty of Economics, University of Tokyo (Japan); ttabuchi@e.u-tokyo.ac.jp

${ }^{\top}$ CORE, Université catholique de Louvain (Belgium), PSE (France), and CEPR; jacques.thisse@uclouvain.be
} 


\section{Introduction}

The aim of this paper is to study how progressive trade liberalization affects countries' industrial structure through both the channel of entrepreneurship and the process of creation/destruction of firms. By lowering trade costs, a deeper economic integration fosters more competition from abroad, which tends to lower prices and profits on the domestic market. This in turn reduces the incentives for individuals to start a new business. However, by facilitating exports lower trade costs make the foreign market bigger, which tend to compensate entrepreneurs for their lower markups. The outcome of this trade-off is, therefore, a priori undetermined. Moreover, besides market conditions, the decision of an individual to establish a firm also depends on her personal characteristics. Thus, we must account for the fact that economies are populated with individuals who are not born with the same abilities and/or do not face the same outside option. This in turn will lead us to view firms as having heterogeneous entry costs.

For a large number of observers, economic development should lead to the progressive disappearance of entrepreneurship (see, e.g., Lucas, 1978). Yet, one of the most striking and solid facts stressed by the economic and business literature devoted to entrepreneurship is the existence of a U-shaped relationship between the rate of new enterprises in the manufacturing and service sectors and the level of economic development among developed countries. More precisely, there has been a steady decline in entrepreneurship from 1900 to 1970 with fewer and larger firms. Since then, a reversal of this pattern has emerged with the birth of many small businesses (see Wennekers et al., 2009 for a survey and empirical evidence). The period 1900-1960 has experienced several ups and downs in trade liberalization, so that one can hardly think of it as being one that went through a deep economic integration process (World Bank, 1991; World Trade Organization, 2001). By contrast, the period starting after 1960 has seen a growing number of developed countries dismantling their trade barriers (e.g., the EU, NAFTA). It seems natural, therefore, to investigate the potential links between the rate of new enterprises and the degree of integration. Our results provide a rationale for this relationship that otherwise remains unexplained.

In what follows, we develop a framework that combines (i) a two-country trade setting in which the manufacturing sector operates under monopolistic competition and increasing returns, and (ii) an occupational choice approach in which heterogeneous individuals are entitled to be either a worker in an existing firm or an entrepreneur producing a new variety. The monopolistic competition setting appears to be especially well suited to analyze the creation of small businesses that have a limited market power, while product differentiation allows us to capture the fundamental idea that entrepreneurs are often market-makers. Furthermore, assuming heterogeneous individuals means that they have both idiosyncratic ideas and subjective attitudes 
toward entrepreneurship (Casson, 2005); they also devote personal effort and resources to establishing a firm. The heterogeneity across individuals is translated in our setting in firms facing heterogeneous entry costs.

Our main results all reveal that trade liberalization has contrasted effects on countries through the creation and destruction of local firms. First of all, we find that the large country always retains a more than proportional share of firms, meaning that the home market effect holds (Krugman, 1980). This does not mean, however, that this country always benefits from lower trade costs. Indeed, trade liberalization does not translate into a simple and monotonic process of international specialization. Specifically, we will see that the whole process of economic integration is to be split into two contrasting phases. In the first one, which occurs when trade costs remain relatively high, the industrial basis of the large country grows whereas that of the small country shrinks. Because consumers living in the small country have access to a much wider range of varieties, the local firms lose a substantial market share in their home market, thus reducing the incentives for people to become entrepreneurs. On the contrary, the large country firms benefit from a market expansion effect that leads more people to become entrepreneurs. Consequently, during the first phase of the integration process, countries become more dissimilar and inequality rises.

In the second phase, which is reached when trade costs are low enough, we observe a complete reversal in the foregoing tendencies. On the one hand, trade costs are now sufficiently low for the small country firms to benefit from a much larger market, thus inducing more individuals to become entrepreneurs. On the other hand, because foreign competition is exacerbated by lower trade costs, business is less profitable in the large country. Hence, during the second phase, economic integration fosters convergence between countries. ${ }^{1}$ Combining the foregoing results will then allow us to show, under a mild regularity condition, that the number of firms in the global economy decreases during our first phase, but grows during the second one. To the extent that the degree of development is highly correlated to the level of integration in developed economies, this nonmonotonic process provides a rationale for the U-shaped curve mentioned earlier. In addition, it is well documented that the rate of new firm formation significantly varies across countries (Audretsch and Feldman, 2004). We illustrate this fact by showing how the creation and destruction of firms vary in countries having different sizes.

Before proceeding, note that Krugman (1980) addressed a similar issue in a setting that involves asymmetric countries, monopolistic competition and increasing returns. He showed that the large country accommodates

\footnotetext{
${ }^{1}$ This is to be contrasted with Amiti and Pissarides (2005), who allow for heterogeneous workers in the core-periphery model (Krugman, 1991). Unlike us, they show that decreasing trade costs induce the agglomeration of firms.
} 
a more than proportional share of firms, while lowering trade costs exacerbates the agglomeration of firms in the large country. Our paper differs from Krugman (1980) in two fundamental aspects. First, the number of firms is variable and endogenously determined through the creation and destruction of firms involving heterogeneous entry costs. Second, there is no magnification of the home market effect since, as trade liberalization proceeds, the relative share of the manufacturing sector in the large country increases during the first phase of market integration, but decreases once trade opening is deep enough.

The remaining of the paper is organized as follows. The model and some preliminary results are presented in Section 2. Section 3 studies the impact of trade liberalization on countries' industrial structure, while Section 4 concludes.

\section{The model and intermediate results}

\section{$2.1 \quad$ The economy}

The economy involves two goods and two countries $i=1,2$ with a population of size $m_{1}$ and $m_{2}$, respectively; without loss of generality, we assume that $m_{1} \geq m_{2}$. Individuals are entitled to be either a worker in an existing firm or an entrepreneur launching a firm that produces a new variety. Our focus being on the heterogeneity of firms in terms of entry costs, we choose to model this idea by assuming that potential entrepreneurs have different opportunity costs, thus implying that they incur different costs when they choose to enter the market as an entrepreneur. The entrepreneur's opportunity cost may then be viewed as the entry cost of the corresponding firm. Formally, we assume that an individual of type $\alpha$ is endowed with $\alpha$ efficiency units of labor and 1 unit of entrepreneurship. Types of individuals living in country $i$ are distributed according to the distribution function $F_{i}:\left[\underline{\alpha}_{i}, \bar{\alpha}_{i}\right] \rightarrow\left[0, m_{i}\right]$ with $0 \leq \underline{\alpha}_{i}<\bar{\alpha}_{i}$, which has a differentiable density function $f_{i}$ such that $f_{i}(\alpha)>0$ for all $\alpha \in\left[\underline{\alpha}_{i}, \bar{\alpha}_{i}\right]$.

Individuals are internationally immobile and have the same quasi-linear log-utility with respect to a continuum $N$ of varieties of a (horizontally) differentiated good $(M)$ and a homogeneous good $(A)$ :

$$
U=\mu \ln M+A \quad \mu>0
$$

where the subutility over the varieties is of the CES-type:

$$
M=\left[\int_{0}^{N} q(x)^{\frac{\sigma-1}{\sigma}} \mathrm{d} x\right]^{\frac{\sigma}{\sigma-1}}
$$

with $\sigma>1$ being the elasticity of substitution between any two varieties. Although quasi-linear preferences rank far behind homothetic preferences 
in general equilibrium models of trade, Dinopoulos et al. (2007) show that "quasi-linear preferences behave reasonably well in general-equilibrium settings". Note, however, that our results remain valid when the upper-tier utility is of the Cobb-Douglas type. ${ }^{2}$ We have chosen to work with a quasilinear specification because it allows a simple and neat presentation of our results. All individuals are endowed with $\bar{A}>0$ units of the homogeneous good. The initial endowment $\bar{A}$ is supposed to be larger than $\mu$ for the consumption of this good to be strictly positive at the market outcome. Consequently, our setting involves no income effect.

The differentiated good $M$ is produced by the manufacturing sector under increasing returns and monopolistic competition, using both entrepreneurs and workers. More precisely, producing $q$ units of a variety requires 1 unit of entrepreneurship and $c q$ units of labor (without loss of generality, we set $c=1$ by choosing the unit of good $M$ ). Hence, firms are heterogeneous in terms of entry cost. Indeed, an individual of type $\alpha$ incurs an opportunity cost equal to $\alpha$ when she chooses to operate in the manufacturing sector, so that different firms have different entry costs. ${ }^{3}$ In addition, the total mass $N=n_{1}+n_{2}$ of firms is endogenous since the mass of country- $i$ entrepreneurs $n_{i}$ is endogenous. Finally, for one unit of the differentiated good to arrive at destination, $\tau \geq 1$ units of this good must be sent from the country of origin (the iceberg trade cost); in particular, zero trade cost means $\tau=1$, whereas countries are autarkic when $\tau \rightarrow \infty$. So defined, trade costs allow one to capture various types of impediments to trade such as transport costs and ad valorem tariffs. ${ }^{4}$

The homogeneous good $A$ is supplied under perfect competition using labor as the only input of a constant-returns technology. The unit input requirement is set to one by choice of units.

Recall that our primary purpose is to investigate how progressive decrease in trade costs for the industrial good affects the sectoral structure of each country. In order to isolate this effect, we choose to work with a setting in which workers' wage is equalized between the two countries. This is guaranteed by the assumption of zero trade cost for the homogeneous good, which also enables us to capture the intuitive idea that the homogeneous good is standardized and easy to ship in bulk, whereas the industrial good is more sophisticated and, therefore, costly to trade. This makes the homogeneous good the natural choice for the numéraire. Consequently, in equilibrium, market wages are the same in both countries and equal to 1 .

\footnotetext{
${ }^{2}$ Proofs are available from the authors upon request.

${ }^{3}$ In an alternative interpretation, the entry decision is associated with a personal effort made by individuals. In this context, individuals are heterogenous in the effort cost $\alpha$ borne to become entrepreneurs.

${ }^{4}$ In the absence of income effect, how the proceeds of tariffs are redistributed across individuals does not affect the market outcome provided that the amount transferred to an individual does not depend on her occupation.
} 
This in turn implies that an $\alpha$-type worker has an income equal to $\alpha$. In an entrepreneurship equilibrium to be defined below, an individual of type $\alpha$ in country $i$ becomes an entrepreneur if and only if she earns an salary $w_{i}$ higher than $\alpha$. This has two major implications. First, the entry process displays decreasing returns. The relative cost of firm creation goes up since more and more efficient workers are drawn away from production. Second, workers' average income rises when the mass of firms operating in the manufacturing sector increases. In other words, our model captures the fact that a rising number of entrepreneurs leads to a higher average income across workers (Lucas, 1978).

Note finally that, since $\alpha$ is distributed across entrepreneurs, firms have different entry costs and are, therefore, heterogeneous. Notice the difference of our setting from the one developed by Melitz (2003) and others where firms have different marginal costs.

\subsection{The market equilibrium}

Fixing the number of entrepreneurs $n_{1}$ and $n_{2}$ in each country, we now determine the market equilibrium and the corresponding entrepreneurs' salaries as functions of $n_{1}$ and $n_{2}$. Let $p_{i j}$ denote the producer price set by a firm located in country $i=1,2$ for consumption in country $j=1,2$. The individual demands in countries $i$ and $j \neq i$ for variety $x \in[0, N]$ produced in country $i$ are respectively given by

$$
q_{i i}=\frac{\mu P_{i}^{\sigma-1}}{p_{i i}^{\sigma}} \quad q_{i j}=\frac{\mu P_{j}^{\sigma-1}}{\left(\tau p_{i j}\right)^{\sigma}}
$$

where $P_{i}$ is the price index of the differentiated good in country $i$. Note that $\tau p_{i j}$ is the consumer price paid by consumers in country $j$ for a variety produced in country $i \neq j$, while $p_{i j}$ is the producer price the country- $i$ firm receives. Since in equilibrium all firms located in country $i$ charge the same producer price in country $j=1,2$, the price index in country $i$ is given by

$$
P_{i}=\left[n_{i} p_{i i}^{-(\sigma-1)}+n_{j}\left(\tau p_{j i}\right)^{-(\sigma-1)}\right]^{-\frac{1}{\sigma-1}} .
$$

Note that (2.1) implies that a country- $i$ individual consumes $\mu / P_{i}$ units of the manufactured goods, thus implying that her expenditure on this good is equal to $\mu$. Therefore, country-i's expenditure on $\operatorname{good} M$ is constant and equal to $\mu m_{i}$.

The profit of a country- $i$ firm is as follows:

$$
\pi_{i}=\left(p_{i i}-1\right) q_{i i} m_{i}+\left(p_{i j}-1\right) \tau q_{i j} m_{j}-w_{i}
$$

because $\tau q_{i j}$ units must be produced in country $i$ for $q_{i j}$ units to be consumed in country $j \neq i$, so that the revenue the firm receives is $p_{i j} \times \tau q_{i j} m_{j}$, while 
the variable cost is $1 \times \tau q_{i j} m_{j}$. This expression implies that the equilibrium producer prices are given by

$$
p_{i i}^{*}=p_{i j}^{*}=\frac{\sigma}{\sigma-1} .
$$

Let $\phi:=\tau^{1-\sigma} \in[0,1]$ be the degree of trade openness: a larger value of $\phi$ means lower trade costs, with $\phi=0$ when $\tau \rightarrow \infty$ and $\phi=1$ when $\tau=1$. Then, the equilibrium price index is expressed as

$$
P_{i}=\frac{\sigma}{\sigma-1}\left(n_{i}+\phi n_{j}\right)^{-\frac{1}{\sigma-1}} .
$$

Under free entry and exit, whence zero profits, the equilibrium entrepreneur income in country $i$ is given by a firm's operating profits:

$$
w_{i}\left(n_{i}, n_{j}\right)=\frac{1}{\sigma}\left(\frac{\mu m_{i}}{n_{i}+\phi n_{j}}+\phi \frac{\mu m_{j}}{n_{j}+\phi n_{i}}\right) .
$$

Thus, the equilibrium income prevailing in country $i$ decreases with the number of entrepreneurs in this country. It also decreases with the number of entrepreneurs in country $j$ because trade makes the two national labor markets interdependent through the mass of varieties they trade. Last, since operating profits are higher, a stronger preference for the industrial good (i.e., larger $\mu$ ) and/or more differentiated varieties (i.e., lower $\sigma$ ) leads to higher equilibrium salaries.

The expression (2.3) may be given a very intuitive interpretation. The first bracketed term is the revenue gleaned by a country- $i$ firm in its domestic market, whereas the second stands for the revenue gleaned in the foreign market, which is "discounted" by $\phi \in[0,1]$ on account of the resources needed to sell abroad. All firms compete for the total expenditure on the manufactured good spent by country-i's residents, which is equal to $\mu m_{i}$. This "pie" is equally divided among country- $i$ firms, but not between country- $i$ firms and country- $j$ firms because of the existence of trade costs $(0<\phi<1)$. Furthermore, the pie accruing to a country- $i$ firm is distributed between the entrepreneur and the workers according to the shares $\left(p^{*}-1\right) / p^{*}$ and $1 / p^{*}$, respectively, where $p^{*}=\sigma /(\sigma-1)$ is the equilibrium producer price. This implies that an entrepreneur receives a fraction $1 / \sigma$ of the pie. Then, for any given $n_{1}$ and $n_{2}$, the following equality must hold at the market equilibrium:

$$
\sum_{i=1,2} w_{i}\left(n_{1}, n_{2}\right) n_{i}=\frac{\mu}{\sigma}\left(m_{1}+m_{2}\right) .
$$

\subsection{The entrepreneurship equilibrium}

We now describe the equilibrium occupational choices. An $\alpha$-type individual living in country $i$ earns $\alpha$ as a worker and chooses to become an entrepreneur 
if and only if her worker income is less than the earnings she makes as an entrepreneur:

$$
\alpha \leq w_{i}\left(n_{i}, n_{j}\right)
$$

so that the mass of entrepreneurs in this country is given by $F_{i}\left[w_{i}\left(n_{i}, n_{j}\right)\right] .^{5}$ A pair $\left(n_{1}^{*}, n_{2}^{*}\right)$ is an entrepreneurship equilibrium if and only if

$$
n_{1}^{*}=F_{1}\left[w_{1}\left(n_{1}^{*}, n_{2}^{*}\right)\right] \quad n_{2}^{*}=F_{2}\left[w_{2}\left(n_{1}^{*}, n_{2}^{*}\right)\right] .
$$

In the equilibrium, $w_{i}\left(n_{1}^{*}, n_{2}^{*}\right)$ is equal to the highest entry cost paid by the firms operating in country $i$, which is endogenously determined. Observe that $\partial F_{i}\left[w_{i}\left(n_{i}, n_{j}\right)\right] / \partial n_{j}<0$, so that entrepreneurship decisions are strategic substitutes between countries. This property relies on the fact that firms compete across countries and does not depend on the specific features of our model.

Since $w_{i}\left(n_{1}^{*}, n_{2}^{*}\right)=F_{i}^{-1}\left(n_{i}^{*}\right)$ holds whenever $\left(n_{1}^{*}, n_{2}^{*}\right)$ is an entrepreneurship equilibrium for some $\phi$, by equation (2.4) the equilibrium must always lie on the locus of

$$
E\left(n_{1}, n_{2}\right):=F_{1}^{-1}\left(n_{1}\right) n_{1}+F_{2}^{-1}\left(n_{2}\right) n_{2}-\frac{\mu}{\sigma}\left(m_{1}+m_{2}\right)=0
$$

regardless of the value of $\phi$. Observe that this locus is downward sloping in the $n_{1}-n_{2}$ plane because of strategic substitutability of entrepreneurship decisions between countries.

Observation 2.1. The locus of $E\left(n_{1}, n_{2}\right)=0$ is downward sloping.

In other words, if the equilibrium number of entrepreneurs in country $i$, $n_{i}^{*}$, increases, then $n_{j}^{*}$ must decrease in $j$.

It remains to find conditions for an entrepreneurship equilibrium to exist. First, note that (2.3) implies that $w_{i}$ has a minimizer $w_{i}^{\min }>0$ independent of $\sigma$. The continuous function $w_{i}$ also has a maximizer $w_{i}^{\max }$ in the compact set $\left[F\left(w_{1}^{\min }\right), m_{1}\right] \times\left[F\left(w_{2}^{\min }\right), m_{2}\right]$. Assume that the interval $\left(\underline{\alpha}_{i}, \bar{\alpha}_{i}\right)$ is wide enough to include $\left[w_{i}^{\min }, w_{i}^{\max }\right]$, which implies that there are always some individuals with sufficiently low $\alpha$ who choose to become entrepreneurs and some with sufficiently high $\alpha$ who choose to become workers, whatever the others' choice. Under these conditions, we may restrict the domain of $F_{i} \circ w_{i}$ over the compact and convex set $\left[F_{1}\left(w_{1}^{\min }\right), F_{1}\left(w_{1}^{\max }\right)\right] \times$ $\left[F_{2}\left(w_{2}^{\min }\right), F_{2}\left(w_{2}^{\max }\right)\right]$. Furthermore, the continuous function $F_{i} \circ w_{i}$ takes its value in $\left[F_{i}\left(w_{i}^{\min }\right), F_{i}\left(w_{i}^{\max }\right)\right]$ because $F_{i}$ is increasing. Hence, Brouwer's fixed point theorem implies that the mapping $\left(F_{1} \circ w_{1}, F_{2} \circ w_{2}\right)$ has a fixed point in the restricted domain of $\left(n_{1}, n_{2}\right)$, and this point is an entrepreneurship equilibrium. We will assume throughout the rest of the paper that $\left[w_{i}^{\min }, w_{i}^{\max }\right] \subset\left(\underline{\alpha}_{i}, \bar{\alpha}_{i}\right)$ for $i=1,2$.

\footnotetext{
${ }^{5}$ An individual being negligible, her occupational choice has no impact on the mass of available varieties. Thus, maximizing income amounts here to maximizing utility.
} 
In the next section, we study how the shares of entrepreneurs-firms in both countries, whence the size and the international distribution of the manufacturing sector, react to gradual trade opening.

\section{The impact of trade opening}

In order to focus on the interactions between country size and trade openness, we consider the case in which the type distributions in the two countries are identical up to a scale parameter that reflects the country size, i.e., $\left[\underline{\alpha}_{i}, \bar{\alpha}_{i}\right]=[\underline{\alpha}, \bar{\alpha}]$, and $F_{i}(\alpha)=m_{i} G(\alpha)$ for a common distribution function $G:[\underline{\alpha}, \bar{\alpha}] \rightarrow[0,1]$. We assume that $G$ has a differentiable density $g$ and $g(\alpha)>0$ for all $\alpha \in[\underline{\alpha}, \bar{\alpha}]$. Accordingly, we focus on $s_{i}:=n_{i} / m_{i}$, the fraction of entrepreneurs in each country $i$. So, from now on, we refer to $\left(s_{1}^{*}(\phi), s_{2}^{*}(\phi)\right)$ as being the entrepreneurship equilibrium.

\subsection{National industrialization}

It follows directly from $(2.5)$ that $\left(s_{1}^{*}(\phi), s_{2}^{*}(\phi)\right)$ is an entrepreneurship equilibrium if and only if $s_{1}^{*}(\phi)$ and $s_{2}^{*}(\phi)$ satisfy the following two conditions:

$$
\begin{aligned}
& \bar{D}_{1}\left(s_{1}, s_{2} ; \phi\right):=G\left(\bar{w}_{1}\left(s_{1}, s_{2} ; \phi\right)\right)-s_{1}=0 \\
& \bar{D}_{2}\left(s_{1}, s_{2} ; \phi\right):=G\left(\bar{w}_{2}\left(s_{1}, s_{2} ; \phi\right)\right)-s_{2}=0
\end{aligned}
$$

where $\bar{w}_{i}:[0,1]^{2} \times[0,1] \rightarrow \mathbb{R}$ is the salary of an entrepreneur in country $i$, which is defined by

$$
\bar{w}_{i}\left(s_{1}, s_{2} ; \phi\right)=\frac{1}{\sigma}\left(\frac{\mu m_{i}}{m_{i} s_{i}+\phi m_{j} s_{j}}+\frac{\phi \mu m_{j}}{m_{j} s_{j}+\phi m_{i} s_{i}}\right) .
$$

It is readily verified that, for any $\left(s_{1}, s_{2}\right), \partial \bar{D}_{i} / \partial s_{j}<0$ for $i, j=1,2$. Furthermore, we have

$$
\left|\frac{\partial \bar{D}_{1}}{\partial s_{1}} / \frac{\partial \bar{D}_{1}}{\partial s_{2}}\right|>\left|\frac{\partial \bar{D}_{2}}{\partial s_{1}} / \frac{\partial \bar{D}_{2}}{\partial s_{2}}\right|
$$

To show it, observe that

$$
\left|\frac{\partial \bar{D}_{1}}{\partial s_{1}} / \frac{\partial \bar{D}_{1}}{\partial s_{2}}\right|>\left|\frac{\partial G\left(\bar{w}_{1}\right)}{\partial s_{1}} / \frac{\partial G\left(\bar{w}_{1}\right)}{\partial s_{2}}\right|=\left|\frac{\partial \bar{w}_{1}}{\partial s_{1}} / \frac{\partial \bar{w}_{1}}{\partial s_{2}}\right|
$$

while

$$
\left|\frac{\partial \bar{D}_{2}}{\partial s_{1}} / \frac{\partial \bar{D}_{2}}{\partial s_{2}}\right|<\left|\frac{\partial G\left(\bar{w}_{2}\right)}{\partial s_{1}} / \frac{\partial G\left(\bar{w}_{2}\right)}{\partial s_{2}}\right|=\left|\frac{\partial \bar{w}_{2}}{\partial s_{1}} / \frac{\partial \bar{w}_{2}}{\partial s_{2}}\right| .
$$

The desired result then follows from

$$
\left|\frac{\partial \bar{w}_{1}}{\partial s_{1}} \cdot \frac{\partial \bar{w}_{2}}{\partial s_{2}}\right| \geq\left|\frac{\partial \bar{w}_{1}}{\partial s_{2}} \cdot \frac{\partial \bar{w}_{2}}{\partial s_{1}}\right|
$$

which always holds. 
Observation 3.1. In the $s_{1}-s_{2}$ plane,

1. the locus of $\bar{D}_{i}\left(s_{1}, s_{2}\right)=0$ is downward sloping;

2. $\bar{D}_{i}\left(t_{1}, t_{2}\right)>0$ if $\left(t_{1}, t_{2}\right)$ belongs to the south-west domain delineated by $\bar{D}_{i}\left(s_{1}, s_{2}\right)=0$, while $\bar{D}_{i}\left(t_{1}, t_{2}\right)<0$ if $\left(t_{1}, t_{2}\right)$ belongs to the north-east domain; and

3. at any entrepreneurship equilibrium $\left(s_{1}^{*}, s_{2}^{*}\right), \bar{D}_{1}\left(s_{1}, s_{2}\right)=0$ is steeper than $\bar{D}_{2}\left(s_{1}, s_{2}\right)=0$.

By continuity, the third statement implies that the equilibrium $\left(s_{1}^{*}(\phi), s_{2}^{*}(\phi)\right)$ is unique for any $\phi$.

When each country is in autarky $(\phi=0)$ or when the two countries are fully integrated $(\phi=1)$, the entrepreneurs' salary is independent of the country size because

$$
\bar{w}_{i}(s, s ; 0)=\bar{w}_{i}(s, s ; 1)=\frac{\mu}{\sigma s}
$$

for any $s$ and $m_{1}, m_{2}$. Since

$$
\bar{D}_{i}(s, s ; 0)=\bar{D}_{i}(s, s ; 1)=G\left(\frac{\mu}{\sigma s}\right)-s
$$

holds regardless of the value of $m_{1}$ and $m_{2}$, it must be that $\bar{D}_{i}(\bar{s}, \bar{s} ; 0)=$ $\bar{D}_{i}(\bar{s}, \bar{s} ; 1)=0$, where $\bar{s} \in(0,1)$ is the unique solution to the equation

$$
G\left(\frac{\mu}{\sigma s}\right)-s=0 .
$$

Thus,

$$
s_{1}^{*}(0)=s_{2}^{*}(0)=s_{1}^{*}(1)=s_{2}^{*}(1)=\bar{s} .
$$

In other words, size does not matter for the share of entrepreneurs in the two polar cases in which trading is either prohibitively expensive or costless. Note, however, that all individuals are better off in the latter than in the former case because they have access to a wider array of varieties.

Let us now come to the more interesting case in which $0<\phi<1$. We then have:

Observation 3.2. (i) If $m_{1}=m_{2}$, then $s_{1}^{*}(\phi)=s_{2}^{*}(\phi)=\bar{s}$ for all $\phi \in(0,1)$.

(ii) If $m_{1}>m_{2}$, then $0<s_{2}^{*}(\phi)<s_{1}^{*}(\phi)<1$ for all $\phi \in(0,1)$.

Proof. (i) If $m_{1}=m_{2}$, then (3.1) implies that $\bar{w}_{i}(s, s ; \phi)$ is independent of $m_{1}$ and $m_{2}$. Hence, we have $s_{1}^{*}(\phi)=s_{2}^{*}(\phi)=\bar{s}$ for all $\phi \in(0,1)$.

(ii) If $m_{1}>m_{2}$, then we have $\bar{D}_{1}(\bar{s}, \bar{s} ; \phi)>0$ and $\bar{D}_{2}(\bar{s}, \bar{s} ; \phi)<0$ for all $\phi \in(0,1)$. By Observation 3.1, this implies that $\left(s_{1}^{*}(\phi), s_{2}^{*}(\phi)\right)$ lies below the bisector, i.e., $s_{1}^{*}(\phi)>s_{2}^{*}(\phi)$ for all $\phi \in(0,1)$. 
Since $w_{2}^{\min }>\underline{\alpha}$ by assumption, it must be that $\bar{D}_{2}\left(s_{1}, 0 ; \phi\right)>0$ for any $s_{1}$ and $\phi$. This implies that $\bar{D}_{2}\left(s_{1}, 0 ; \phi\right)=0$ never intersects the $s_{1}$-axis, which in turn implies that $\left(s_{1}^{*}(\phi), s_{2}^{*}(\phi)\right)$ never lies on the $s_{1}$-axis, i.e., $s_{2}^{*}(\phi)>0$ for all $\phi \in(0,1)$. Likewise, $w_{1}^{\max }<\bar{\alpha}$ implies $s_{1}^{*}(\phi)<1$ for all $\phi \in(0,1)$. $\|$

From (2.6), observe that the equilibrium $\left(s_{1}^{*}(\phi), s_{2}^{*}(\phi)\right)$ always lies on the locus of

$$
\bar{E}\left(s_{1}, s_{2}\right):=m_{1} G^{-1}\left(s_{1}\right) s_{1}+m_{2} G^{-1}\left(s_{2}\right) s_{2}-\frac{\mu}{\sigma}\left(m_{1}+m_{2}\right)=0 .
$$

As in Observation 2.1, this locus is downward sloping in the $s_{1}-s_{2}$ plane. This implies that, as $\phi$ increases from 0 to $1, s_{1}^{*}(\phi)$ and $s_{2}^{*}(\phi)$ always move in opposite directions. Specifically, the equilibrium $\left(s_{1}^{*}(\phi), s_{2}^{*}(\phi)\right)$ starts from $(\bar{s}, \bar{s})$, moves continuously along the locus $\bar{E}\left(s_{1}, s_{2}\right)$, and ends up at $(\bar{s}, \bar{s})$. We will show below that $\left(s_{1}^{*}(\phi), s_{2}^{*}(\phi)\right)$ changes its direction only once. Since $\left(s_{1}^{*}(\phi), s_{2}^{*}(\phi)\right)$ is given by the intersection point of $\bar{E}\left(s_{1}, s_{2}\right)=0$ and $\bar{D}_{1}\left(s_{1}, s_{2} ; \phi\right)=0$, it suffices to show that, as $\phi$ increases from 0 to 1 , $\bar{D}_{1}\left(s_{1}, s_{2} ; \phi\right)=0$ changes its direction only once.

Lemma 3.3. For any given $\left(s_{1}, s_{2}\right)$, the equation $\bar{D}_{1}\left(s_{1}, s_{2} ; \phi\right)=0$ has at most two solutions in terms of $\phi$.

Proof. Fix any point $\left(s_{1}, s_{2}\right)$. We claim that

$$
\frac{\partial \bar{D}_{1}}{\partial \phi}=g\left(\bar{w}_{1}\right) \frac{\partial \bar{w}_{1}}{\partial \phi}
$$

changes its sign at most once. Since $g(\cdot)>0$, it is sufficient to show that $\partial \bar{w}_{1} / \partial \phi=0$ has at most one solution, which can be established by direct computation. Hence, $\bar{D}_{1}\left(s_{1}, s_{2} ; \phi\right)$ changes its slope at most once, which in turn implies that $\bar{D}_{1}\left(s_{1}, s_{2} ; \phi\right)=0$ has at most two solutions in $\phi$. \|

This has the following implication.

Observation 3.4. As $\phi$ increases from 0 to $1,\left(s_{1}^{*}(\phi), s_{2}^{*}(\phi)\right)$ changes its direction only once.

Proof. Fix any point $\left(t_{1}, t_{2}\right)$ on the locus of $\bar{E}\left(s_{1}, s_{2}\right)=0$. By continuity of the equilibrium with respect to $\phi$, it is sufficient to show that $\left(t_{1}, t_{2}\right)$ becomes an equilibrium for at most two distinct values of $\phi$. Furthermore, $\left(t_{1}, t_{2}\right)$ is an equilibrium only if it satisfies $\bar{D}_{1}\left(t_{1}, t_{2} ; \phi\right)=0$ for some $\phi$. Finally, Lemma 3.3 implies that there exist at most two such $\phi$ 's. |

To sum up, we have:

Proposition 3.5. For all $\phi \in[0,1]$, there exists a unique entrepreneurship equilibrium $\left(s_{1}^{*}(\phi), s_{2}^{*}(\phi)\right)$.

(i) For any $m_{1}$ and $m_{2}, s_{1}^{*}(0)=s_{2}^{*}(0)=s_{1}^{*}(1)=s_{2}^{*}(1)=\bar{s}$. 


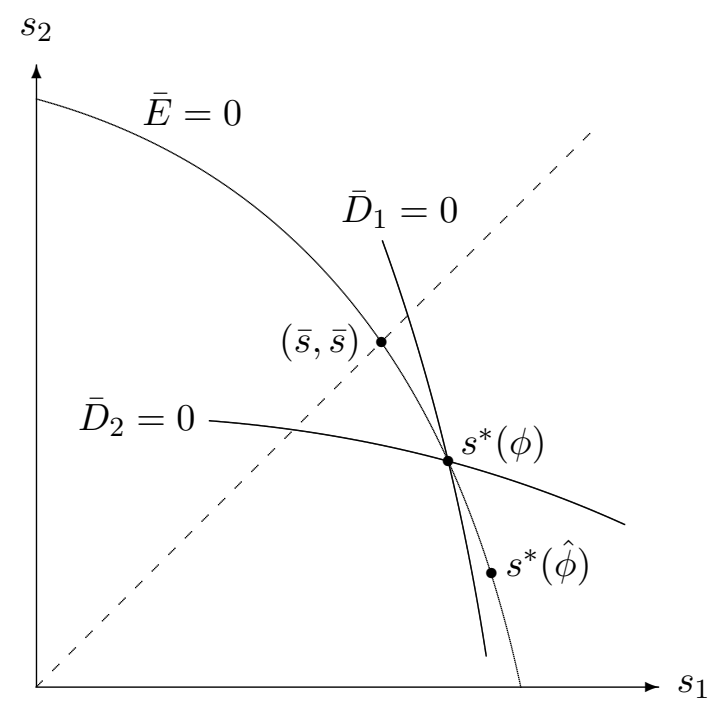

Figure 1: Entrepreneurship equilibrium

(ii) If $m_{1}>m_{2}$, then $s_{1}^{*}(\phi)>s_{2}^{*}(\phi)>0$ for all $\phi \in(0,1)$. Furthermore, there exists a unique $\hat{\phi} \in(0,1)$ such that $\bar{s}<s_{1}^{*}(\phi)<s_{1}^{*}\left(\phi^{\prime}\right)$ and $\bar{s}>s_{2}^{*}(\phi)>$ $s_{2}^{*}\left(\phi^{\prime}\right)$ when $0<\phi<\phi^{\prime} \leq \hat{\phi}$, while $s_{1}^{*}(\phi)>s_{1}^{*}\left(\phi^{\prime}\right)>\bar{s}$ and $s_{2}^{*}(\phi)<s_{2}^{*}\left(\phi^{\prime}\right)<\bar{s}$ when $\hat{\phi} \leq \phi<\phi^{\prime}<1$.

(iii) If $m_{1}=m_{2}$, then $s_{1}^{*}(\phi)=s_{2}^{*}(\phi)=\bar{s}$ for all $\phi \in(0,1)$.

Figure 1 depicts the entrepreneurship equilibrium as well as the relevant loci. Since both countries exhibit a reversal in the evolution of their industrial structure at $\hat{\phi}$, we refer to the interval $(0, \hat{\phi})$ as describing the first phase of the integration process, while $(\hat{\phi}, 1)$ corresponds to the second one.

Proposition 3.5 has several important implications. First, the share of entrepreneurs is always larger in the large country than in the small country. This implies that the large country is relatively more specialized in the manufacturing sector than the small country. This in turn means that the salary of an entrepreneur is higher in the large country than in the small one. Therefore, because $P_{1}^{*}<P_{2}^{*}$, both entrepreneurs and workers in country 1 are better off than their counterpart in country 2. Accordingly, we may safely conclude that, once countries have different sizes, spatial frictions in trade generate asymmetries in the international distribution of income and welfare.

Second, the global economy displays a home market effect. Recall that such an effect arises when the large country accommodates a more than proportional share of firms (Krugman, 1980). The share of country 1's industrial firms in the global economy is such that

$$
\frac{n_{1}^{*}(\phi)}{n_{1}^{*}(\phi)+n_{2}^{*}(\phi)}=\frac{m_{1} s_{1}^{*}(\phi)}{m_{1} s_{1}^{*}(\phi)+m_{2} s_{2}^{*}(\phi)}>\frac{m_{1}}{m_{1}+m_{2}}
$$


because $s_{1}^{*}(\phi)>s_{2}^{*}(\phi)$ once $0<\phi<1$ and $m_{1}>m_{2}$. In other words, the share of firms in the large country always exceeds its relative size.

Last, trade liberalization has a dramatic impact on each country's degree of industrialization. Indeed, trade links the two countries in a way such that one country always develops its industry at the expense of the other. More precisely, during the first phase of integration the number of entrepreneurs increases in the large country but decreases in the small one. This means that the large country gets more industrialized, whereas the small one experiences de-industrialization. During the first phase, the per capita income increases in the large country and decreases in the small one because both $s_{1}^{*}$ and $w_{1}^{*}$ rise, whereas $s_{2}^{*}$ and $w_{2}^{*}$ fall. The first phase thus agrees with the home market effect in which, as trade costs go down, the share of firms grows in the large country, but decreases in the small one. However, there is no magnification effect as integration proceeds since the relative share of manufacturing in the large country no longer increases with further trade liberalization. Quite the opposite, during the second phase, the small country gradually recoups its industrial basis and the two industrial structures converge.

The above pattern may be explained as follows. As discussed in the introduction, trade liberalization gives rise to two conflicting effects that shape the global economy. The former, called the market expansion effect, finds its origin in the fact that exporting becomes easier, thus strengthening the incentives to become an entrepreneur. The latter, which we refer to as the market crowding effect, is the mirror image of the former: as it becomes easier for each country to import new varieties, the incentives to become an entrepreneur are weaker. Because of strategic substitutability of entrepreneurship decisions between countries, if one effect dominates the other in one country, the reverse must hold in the other one. In order to study the behavior of these two effects as $\phi$ varies from 0 to 1 , we take the partial derivative of (3.1) with respect to $\phi$ :

$$
\begin{aligned}
\frac{\partial \bar{w}_{i}}{\partial \phi}\left(s_{1}, s_{2} ; \phi\right)=\frac{1}{\sigma} & {\left[-\frac{\mu m_{i}}{m_{i} s_{i}+\phi m_{j} s_{j}} \cdot \frac{m_{j} s_{j}}{m_{i} s_{i}+\phi m_{j} s_{j}}\right.} \\
& \left.+\frac{\mu m_{j}}{m_{j} s_{j}+\phi m_{i} s_{i}}-\frac{\phi \mu m_{j}}{m_{j} s_{j}+\phi m_{i} s_{i}} \cdot \frac{m_{i} s_{i}}{m_{j} s_{j}+\phi m_{i} s_{i}}\right] .
\end{aligned}
$$

Hence, the impact of trade opening on a country- $i$ firm can be decomposed in three effects: (i) the first term represents the market crowding effect in the home country, (ii) the second is the market expansion effect in the foreign country, and (iii) the third is the market crowding effect in the foreign country. In these terms, $\phi \mu m_{j}$ is the effective size of the foreign market for a country- $i$ firm, while $m_{i} s_{i}+\phi m_{j} s_{j}$ is the effective number of firms competing in country $i$. 
Clearly, when $\phi=0$, the third term vanishes and we obtain

$$
\frac{\partial \bar{w}_{i}}{\partial \phi}(\bar{s}, \bar{s} ; 0)=\frac{1}{\sigma}\left[-\frac{\mu m_{i}}{m_{i} \bar{s}} \cdot \frac{m_{j} \bar{s}}{m_{i} \bar{s}}+\frac{\mu m_{j}}{m_{j} \bar{s}}\right]=\frac{1}{\sigma} \frac{\mu}{\bar{s}}\left(-\frac{m_{j}}{m_{i}}+1\right) .
$$

Hence, for a country-1 firm, the market crowding effect in the home market is dominated by the market expansion effect since $m_{1}>m_{2}$, whereas the opposite holds for the small country. Since both countries have the same share $\bar{s}$ of firms, the market expansion effect is equalized (equal to $\mu / \bar{s}$ ) for firms in both countries. On the other hand, the market crowing effect is less (more) severe in the large (small) country, which works positively (negatively) for the incentives of the large (small) country individuals to become an entrepreneur.

When $\phi=1$, we have

$$
\begin{aligned}
\frac{\partial \bar{w}_{i}}{\partial \phi}(\bar{s}, \bar{s} ; 1)= & \frac{1}{\sigma}\left[-\frac{\mu m_{i}}{m_{i} \bar{s}+m_{j} \bar{s}} \cdot \frac{m_{j} \bar{s}}{m_{i} \bar{s}+m_{j} \bar{s}}\right. \\
& \left.+\frac{\mu m_{j}}{m_{j} \bar{s}+m_{i} \bar{s}}-\frac{\mu m_{j}}{m_{j} \bar{s}+m_{i} \bar{s}} \cdot \frac{m_{i} \bar{s}}{m_{j} \bar{s}+m_{i} \bar{s}}\right] \\
= & \frac{1}{\sigma} \cdot \frac{-\mu m_{i}+\mu m_{j}}{\left(m_{i}+m_{j}\right) \bar{s}} \cdot \frac{m_{j}}{m_{i}+m_{j}} .
\end{aligned}
$$

In this case, the crowding effects are equalized for both countries since they are fully integrated and have the same effective number $m_{1} \bar{s}+m_{2} \bar{s}$ of firms. On the other hand, the market expansion effect is smaller (larger) for the large (small) country, which works negatively (positively) for the incentives of the large (small) country individuals to become an entrepreneur. Recall that $\mu m_{i}$ is the total expenditure of country- $i$ 's residents on the industrial good and thus is viewed as the market size of country $i$.

Assume now that $\phi \in(0,1)$. First, assuming that $m_{1}>m_{2}$, a marginal increase in the access to the foreign market is always larger for the small country firms than for the large country firms. Second, since $m_{1} s_{1}>m_{2} s_{2}$, the effective number of competing firms in the large country, $m_{1} s_{1}+\phi m_{2} s_{2}$, is bigger than that in the small country, $\phi m_{1} s_{1}+m_{2} s_{2}$, but the difference between those numbers becomes smaller as $\phi$ rises. Consequently, as integration proceeds, the market crowding effect becomes stronger relative to the market expansion effect for the large country firms, and vice versa for the small country firms. What Proposition 3.5 says is that, during the first phase of integration, the market expansion effect dominates the market crowding effect for the large country as it does when $\phi=0$, so that the number of firms in the large country increases while that of the small one decreases. Conversely, during the second phase, the market crowding effect dominates the market expansion effect for the large country as it does when $\phi=1$, so that the large country workers face weaker incentives to get skilled, which in turn implies that some of the small country workers choose to become entrepreneurs. 
Three final remarks are in order. First, it is worth stressing that all the properties derived above hold for any distribution of types. Our main assumption is the quasi-linearity of preferences, which allows us to abstract from the income effect and to isolate the market expansion and crowding effects which go only through the price index. Yet, the inverted U-shaped process remains valid with a Cobb-Douglas utility function. Hence, this result is not a consequence of the absence of an income effect. Second, as shown in Oyama et al. (2009, Appendix A.1), the preceding analysis holds true when firms are heterogeneous in terms of marginal costs as in Melitz (2003) instead of entry costs if individuals know their types before making the entry decision. Last, when both countries have the same size, all results boil down to a trivial outcome in which the two countries keep the same industrial structure during the integration process.

\subsection{Global industrialization}

It remains to study the trajectory of the equilibrium as a function of the degree of openness. As $\phi$ changes, the entrepreneurial income changes, thus inducing some individuals to modify their occupational choice. Clearly, the mass of the individuals who switch occupation depends on the shape of the density function $g$. If this function has a complex form, then so may be the equilibrium trajectory. The following assumption imposes a standard regularity condition on the density $g$ that allows us to obtain a simple and neat characterization of the equilibrium trajectory.

Assumption 3.1. The density function $g$ is $\rho$-concave for some $\rho>-1 / 2$.

Such an assumption is far from being new in the economics literature. ${ }^{6}$ It has been introduced by Caplin and Nalebuff (1991a, 1991b) and used extensively in differentiated oligopoly models (see, e.g., Anderson et al. 1992). Note that $\rho$-concavity with $\rho<0$ is a weaker requirement than log-concavity (0-concavity is equivalent to log-concavity). Hence, our assumption covers the class of log-concave densities, which include many probability distributions such as the Pareto, beta, Dirichlet, exponential, gamma, Laplace, normal, and Gumbel distributions. ${ }^{7}$ Thus, we find it fair to say that our $\rho$-concavity assumption imposes a relatively mild restriction on the density function $g$.

Under this regularity condition, we can show the following.

Lemma 3.6. Under Assumption 3.1, the locus of $\bar{E}\left(s_{1}, s_{2}\right)=0$ is strictly concave.

\footnotetext{
${ }^{6}$ Recall that a function $f$ is $\rho$-concave if $f^{\rho}$ is concave.

${ }^{7}$ As shown by Prékopa (1971), log-concavity may require restrictions on the parameter values for some of these distributions.
} 
Proof. Because $g$ is $-1 / 2$-concave, the Prékopa-Borell theorem implies that $G$ is $\rho^{\prime}$-concave for some $\rho^{\prime}>-1$. This in turn implies that $1 / G$ is strictly convex (Caplin and Nalebuff, 1991b). Given (2.6), it then suffices to show that $d\left(G^{-1}(x) x\right) / d x=\left(G^{-1}\right)^{\prime}(x) x+G^{-1}(x)$ is increasing in $x$ for the statement to hold. Since $\left(G^{-1}\right)^{\prime}(x)=1 / G^{\prime}\left(G^{-1}(x)\right)$ and since $G^{-1}$ is increasing, this is amount to saying that

$$
\frac{G(\alpha)}{G^{\prime}(\alpha)}+\alpha
$$

is increasing in $\alpha$. Taking the derivative of this expression, it is readily verified that this holds if and only if

$$
2\left(G^{\prime}(\alpha)\right)^{2}-G(\alpha) G^{\prime \prime}(\alpha)>0
$$

for all $\alpha$, which means that $1 / G$ is strictly convex. $\|$

The slope of the locus of $E\left(s_{1}, s_{2}\right)=0$ is $-m_{1} / m_{2}$ at $(\bar{s}, \bar{s})$. Provided $m_{1}>m_{2}$, Lemma 3.6 and Observation 2.1 imply that

$$
\left|\frac{d n_{1}^{*}(\phi)}{d \phi}\right|<\left|\frac{d n_{2}^{*}(\phi)}{d \phi}\right|
$$

for all $\phi \neq 0,1, \hat{\phi}$. Therefore, the size of the manufacturing sector in the small country is more sensitive to variations in trade obstacles than in the large one.

Denote by $N^{*}(\phi)$ the total number of firms in the whole economy:

$$
N^{*}(\phi)=m_{1} s_{1}^{*}(\phi)+m_{2} s_{2}^{*}(\phi) .
$$

Since $n_{2}^{*}$ decreases (respectively, increases) faster than $n_{1}^{*}$ (respectively, decreases) over the interval $(0, \hat{\phi})$ (resp., $(\hat{\phi}, 1))$, we have:

Proposition 3.7. Suppose that $m_{1} \neq m_{2}$. Under Assumption 3.1, $N^{*}(\phi)$ decreases over $(0, \hat{\phi})$ but increases over $(\hat{\phi}, 1)$.

In other words, as trade barriers are gradually removed, the global economy experiences the destruction of firms and the shrinking of variety, but faces the creation of firms and the widening of variety when international integration gets sufficiently deep. By making the whole array of varieties available in the global economy accessible to all consumers, the first integration phase induces fewer individuals to become entrepreneurs. On the other hand, during the second phase, the global market is sufficiently integrated to make the incentives to get entrepreneurs stronger and to bring the level of industrialization back to its initial level.

At this stage, it is worth stressing the analogy between the foregoing proposition and the bell-shaped curve of spatial development obtained in 
economic geography (Ottaviano and Thisse, 2004). In the former, there is no labor mobility between countries, but occupational choice makes endogenous the industrial structure of each country. In the latter, there is no sectoral mobility of labor, but the migration of workers between countries permits the emergence of economic agglomerations. The analogy lies in the fact that, during the first phase of integration, the two countries become more dissimilar, while their industrial structure converges during the second one.

\section{Conclusion}

The general press and anti-globalization groups often maintain that international economic integration leads to a more uniform and grey world. In view of our results, they seem to be right since market integration leads to the destruction of firms and varieties when the national economies become involved in the first stages of trade liberalization. In particular, developing countries (here the country with the small market and industrial basis) experience de-industrialization, an argument that lies behind the importsubstituting industrialization policies put forward in the 1960s (Hirschman, 1968). However, our results also suggest that a deeper economic integration leads to more diversity through the creation of new firms. In particular, the integration of developing countries to the world market might well be beneficial to them, as illustrated by the East Asian Miracle. Small countries then benefit from market integration by regaining market share in the manufacturing sector. What makes the whole process politically non-trivial is the fact that trading partners are unevenly affected as trade barriers gradually disappear. In the first phase, the share of developed countries (here the country with the large market and industrial basis) in manufacturing grows at the expense of that of developing countries, whereas the opposite holds in the second phase.

\section{References}

[1] Amiti, M. and C.A. Pissarides (2005), "Trade and industrial location with heterogeneous labor," Journal of International Economics 67, 392-412.

[2] Anderson, S.P., A. de Palma and J.-F. Thisse (1992), Discrete Choice Theory of Product Differentiation, Cambridge, MA: The MIT Press.

[3] Audretsch, D.B. and M.P. Feldman (2004), "Knowledge spillovers and the geography of innovation," J.V. Henderson and J.-F. Thisse, eds., Handbook of Regional and Urban Economics vol. 4, 2713-39, Amsterdam: North Holland. 
[4] Caplin, A. and B. Nalebuff (1991a), "Aggregation and social choice: A mean voter theorem," Econometrica 59, 1-24.

[5] Caplin, A. and B. Nalebuff (1991b), "Aggregation and imperfect competition: on the existence of equilibrium," Econometrica 59, 25-60.

[6] Casson, M. (2005), Entrepreneurship and the theory of the firm," Journal of Economic Behavior and Organization 58, 327-48.

[7] Dinoupoulos, E., K. Fujiwara and K. Shimomura (2007), "International trade patterns under quasi-linear preferences," mimeo, University of Florida.

[8] Hirschman, A.O. (1968), "The political economy of import-substituting industrialization in Latin America," Quarterly Journal of Economics 82, 1-32.

[9] Krugman, P.R. (1980), "Scale economies, product differentiation, and the pattern of trade," American Economic Review 70, 950-59.

[10] Krugman, P. (1991), "Increasing returns and economic geography," Journal of Political Economy 99, 483-499.

[11] Lucas, R. (1978), "On the size distribution of business firms," Bell Journal of Economics 9, 508-23.

[12] Melitz, M. (2003), "The impact of trade on intraindustry reallocations and aggregate industry productivity," Econometrica 71, 1695-1725.

[13] Ottaviano, G.I.P. and J.-F. Thisse (2004), "Agglomeration and economic geography," J.V. Henderson and J.-F. Thisse, eds., Handbook of Regional and Urban Economics vol. IV, 2563-608, Amsterdam: North Holland.

[14] Oyama, D., Y. Sato, T. Tabuchi and J.-F. Thisse (2009), "On the impact of trade on industrial structures: The role of entry cost heterogeneity," PSE Working Paper 2009-08.

[15] Prékopa, A. (1971) "Logarithmic concave measures with application to stochastic programming," Acta Scientiarum Mathematicarum 32, 30116.

[16] Wennekers, S., A. van Stel, M. Carree and R. Thurik (2009), "The relation between entrepreneurship and economic development: is it Ushaped? Foundations and Trends in Entrepreneurship 5, forthcoming.

[17] World Bank (1991), World Development Report. The Challenge of Development. Oxford: Oxford University Press. 
[18] World Trade Organization (2001), Market access: unfinished business. Post-Uruguay Round inventory and issues. Special Studies 6. 